\title{
The Effectiveness of the Negotiating Entry to the Teaching Philosophy in the Development of Skills Mind Enlightenment and Decision-Making to High School Students
}

\author{
Ahmad Ibrahim Ahmad Abo El Hassan \\ Faculty of Education, South Valley University
}

\begin{abstract}
The currant search aimed to Identify the Effectiveness of the Negotiating entry to the teaching philosophy in the development of skills mind Enlightenment and Decision-making to high school students. The study sample consisted of (60) female students, (30) female students of the Experimental group and (30) of the control group, a hand book has been prepared for female students which contains reform elation to unit as sassed on the female students in the first semester 2016/2017, an instructor manual has been to guide in teaching the unit of the subject of the study, has been prepared also which were negotiating entry, which has been reset study and apply after that on female students ( research group ) the results of study pointed to the following the Effectiveness of the use negotiating entry in teaching philosophy in the development of mind Enlightenment skills and Decision-making to female students of the high school students, these results were from atmosphere which the negotiating entry were provided of thinking excite metal which helped in mind enlightenment development and decision-making.
\end{abstract}

Keywords: Negotiating Entry ; Mind Enlightenment ; Philosophy ; Decision; Making ; High School Students

Citation Abo El Hassan.,Requirements of Electronic Management in the Management of Kindergarten Institutions. SVU-Journal of abstract 2019, Vol.1: pp12 (retrieved from the Journal of Educational Sciences; 2018, No.35; pp 14) .

Copyright: Publisher South Valley University. This is an open access article distributed under the terms of the creative common attribution license, which permits unrestricted use, distribution and reproduction in any medium provided the original author and source are created. 